\title{
Pricing strategy of closed loop supply chain considering different CSR investment modes
}

\author{
Yingluo Yan, and Fengmin Yao* \\ School of Economics and Management, Harbin University of Science and Technology, Harbin \\ 150080, China
}

Keywords: Closed-loop supply chain, Corporate social responsibility, Profit donation, dominate retailer, Pricing decision.

\begin{abstract}
More and more companies are beginning to realize that incorporating corporate social responsibility (CSR) and sustainable development into supply chain strategies and operations can bring them more competitive advantages. In the case that the manufacturer or retailer performs CSR through profit donation, the pricing decision-making problem of closed-loop supply chain (CLSC) with dominant retailer under different CSR investment modes is studied. The decision-making models of CLSC under the manufacturer's and retailer's CSR investment mode are constructed respectively. The conditions for enterprises to fulfil CSR through profit donation and the influence of different CSR investment modes on the pricing of new products and recycling of waste products are discussed. The research shows that no matter what kind of CSR investment mode, only when the consumers are more sensitive to the CSR investment of enterprises, the manufacturer and retailer will fulfil the CSR through profit donation. The CSR investment mode of the manufacturer is more beneficial to consumers, environment, CLSC members and whole system. No matter whether the dominant retailer carries out CSR investment or not, she always obtains more channel profits than the manufacturer.
\end{abstract}

\section{Introduction}

With the continuous development of the global economy and technology, the replacement of household electronic appliances and other products is getting faster and faster, and a large number of waste products are produced, causing resource shortages and environmental pollution problems to become increasingly serious. In order to alleviate the adverse effects of waste products on human life and the environment, countries and enterprises all over the world are trying their best to find out how to recycle and reuse waste products, so as to effectively realize sustainable economic development. In this context, many manufacturers have begun to incorporate recycling and remanufacturing into their production decision-making system to effectively alleviate the contradiction between economic development and resource and environmental issues [1]. In reality, HP, Xerox,

* Corresponding author: fengmin_yao@hrbust.edu.cn 
IBM and other companies have not only achieved good economic benefits through active recycling and remanufacturing of waste products, but also effectively alleviated the pressure from increasingly stringent environmental regulations [1-2]. Therefore, the closed-loop supply chain (CLSC) management can effectively balance the coordinated development of the economy and the environment has received extensive attention from the business community and academia.

On the other hand, as social issues such as food safety, quality defects, and production safety have become more prominent and consumers' awareness of social responsibility has increased, all sectors of society are paying more and more attention to corporate social responsibility (CSR). That is to say, all sectors of society not only expect that enterprises can assume corresponding economic responsibilities, but also need to assume responsibilities to employees, other stakeholders, the environment and society. Related research also shows that CSR not only helps to improve the economic benefits and brand reputation of enterprises, but also helps to increase consumers' willingness to pay for related products $[3,4]$. In this context, more and more companies have begun to incorporate CSR practices into their own development strategies to effectively achieve the coordinated development of economy, society and the environment. Internationally renowned companies such as Alibaba, Huawei, and Ford release CSR report every year to show their efforts and contributions to improving social and environmental benefits this year. At the same time, in recent years, consumers have paid more attention to whether companies actively contribute to the improvement of society and the environment in their business activities. They are also more willing to buy products from companies that actively donate to social welfare organizations or schools [5]. The charity donations have become an important measure for companies to demonstrate CSR. In reality, more and more companies have begun to actively donate to social charity organizations to fulfill CSR. For example, in 2013, Unilever launched the "Green Hatta" donation campaign, which effectively enhanced its brand image and commercial value. In 2015, Wal-Mart launched the "Love Snacks" donation activity and integrated the concept of sustainable development into all links of the supply chain. During the COVID-19 pandemic in 2020, companies such as Xiaomi, Midea, and Alibaba are actively donating to many countries affected by the pandemic.

At present, many scholars have discussed the impact of CSR on CLSC operations. Panda et al. used consumer surplus as an indicator to measure the level of CSR fulfillment by enterprises, and pointed out that the company's CSR behavior can help improve the overall performance of CLSC system [4]. Dai et al. studied the impact of CSR behavior on the pricing decision and coordination of the remanufacturing supply chain under the condition that consumers have differences in payment for new products and remanufactured products [6]. Liu et al. studied the influence of CSR preference and the proportion of green consumers on the selection of reverse recycling channels, pricing and recycling ratios in CLSC [7]. Wang et al. studied the impact of government subsidy incentives and corporate product donations on the CLSC recycling and pricing decisions under different decision-making modes [8]. Modak et al. constructed four recycling decision models for the CLSC under the manufacturer's CSR input, and studied the influence of manufacturer's CSR input behavior on the choice of the best recycling channel in the CLSC [9].

Although existing studies have explored the impact of CSR on the operation of CLSC from multiple aspects, there are few studies involving the operation of a retailer-led CLSC and the CSR investment (profit donations) of different member companies. However, with the rapid development of the retail industry and the rise of a large number of retail chain companies (such as Wal-Mart, Carrefour, and JingDong), more and more industries have begun to form an industry pattern with retailers as the dominant player. Therefore, taking the retailer-dominated CLSC composed of JD and Midea as an example, considering that 
JD and Midea have donated to social welfare organizations at different times. Based on this, this paper will construct the CLSC decision-making model in two situations where the manufacturer or retailer makes CSR investment (profit donations) and study the conditions for different enterprises that making profit donation in the CLSC and the impact of different CSR investment modes on the CLSC operation decision.

\section{Problem description and related assumptions}

In this paper, we consider a single period CLSC system composed of a manufacturer and a dominant retailer. Among them, the manufacturer is responsible for the production of new products and the recycling and remanufacturing of waste products, while the retailer is responsible for the sales of new products. Referring to the research of references [2], the manufacturer and retailer conduct Stackelberg game under complete information, and assume that there is no difference in performance and appearance between products produced with waste product parts and products produced with new raw materials, they are sold as new products at the same price in the market.

At the same time, it is assumed that both the manufacturer and retailer have the awareness of CSR investment. Similar to the research hypothesis in reference [9], the CSR invest behavior of the manufacturer or retailer means that the manufacturer or retailer directly donates a certain amount of money to social welfare organizations very time they wholesale or sell a unit of new product. Referring to Modak et al. [9], the demand function of the CLSC is as follows

$$
q=a-\beta p+\theta d
$$

where, $a$ represents the market potential, $a>0$ and $a>\beta p, p$ represents the retail price of new product, $\beta$ represents the price sensitivity of consumers to new products, $d$ represents the amount of direct donation (CSR investment level) by the manufacturer or retailer to a social good organization for each unit of new product wholesale or sale, $\theta$ represents the sensitivity coefficient of consumers to CSR invest level. Other symbols and variables are as follows.

$w$ represents the wholesale prices of new products, $c_{m}$ and $c_{r}$ respectively represent the manufacturer's unit production cost of new products and the unit remanufacturing cost of remanufacturing waste products, A represents the manufacturer's unit transfer payment to consumers when recycling waste products, without loss of generality, $\Delta_{1}=c_{m}-c_{r}-A>0 . c(\tau)=k \tau^{2}$ and $h(d)=g d^{2}$ respectively represent the cost of recycling effort and the fixed cost of CSR investment [2,9], $k$ and $g$ respectively represent the scale parameter of recycling effort and the scale parameter of CSR investment, $k>0, g>0$.

In order to ensure that the relevant expressions have certain economic feasibility, similar to the assumptions in literature [2], we require the scale parameter $k>\frac{g \beta\left(a-\beta c_{m}\right) \Delta_{1}+g \beta^{2} \Delta_{1}^{2}}{4 g \beta-(\theta-\beta)^{2}}$ and $g>\frac{\theta(\theta-\beta)}{2 \beta}$. 


\section{Construction decision model of CLSC considering different CSR investment modes}

\subsection{The decision-making model under manufacturer's CSR investment mode (Model M)}

Under the Model M, the manufacturer makes CSR investment, and the profit functions of the manufacturer and the retailer are respectively

$$
\begin{gathered}
\pi_{m}^{M}(w, d, \tau)=\left(w-c_{m}-d\right)(a-\beta p+\theta d)+\left(c_{m}-c_{r}-A\right) \tau(a-\beta p+\theta d)-g d^{2}-k \tau^{2} \\
\pi_{r}^{M}(m)=m(a-\beta p+\theta d)
\end{gathered}
$$

Theorem 1 Under the Model $M$, the optimal wholesale and retail prices for new products are respectively $w^{M *}=\frac{a g \Delta_{4}+\Delta_{5}}{2 \Delta_{3}}, p^{M *}=\frac{2 a g \beta \Delta_{6}+\Delta_{7}}{2 \beta \Delta_{3}}$; the optimal recovery rate and CSR investment level are respectively $\tau^{M *}=\frac{g \beta\left(a-\beta c_{m}\right) \Delta_{1}}{2 \Delta_{3}}, d^{M *}=\frac{k(\theta-\beta)\left(a-\beta c_{m}\right)}{2 \Delta_{3}} ;$ the optimal market demand is $q^{M *}=\frac{k g \beta\left(a-\beta c_{m}\right)}{\Delta_{3}}$. The total profits of manufacturer, retailer and system are respectively $\pi_{m}^{M *}=\frac{k g\left(a-\beta c_{m}\right)^{2}}{4 \Delta_{3}}, \pi_{r}^{M *}=\frac{k g\left(a-\beta c_{m}\right)^{2}}{2 \Delta_{3}}, \pi_{s}^{M *}=\frac{3 k g\left(a-\beta c_{m}\right)^{2}}{4 \Delta_{3}}$. Where ,
$4 k-\beta \Delta_{1}^{2}=\Delta_{2}$
$g \beta \Delta_{2}-k(\theta-\beta)^{2}=\Delta_{3}$
$2 k-\beta \Delta_{1}^{2}=\Delta_{4}$
$g \beta c_{m}\left(6 k-\beta \Delta_{1}^{2}\right)+k(\theta-\beta)\left(a-(2 \theta-\beta) c_{m}\right)=\Delta_{5}$
$3 k-\beta \Delta_{1}^{2}=\Delta_{6}$

$2 k g \beta^{2} c_{m}+k(\theta-\beta)\left(2 a \beta-\theta\left(a+\beta c_{m}\right)\right)=\Delta_{7}$. Under the assumption of scale parameter $k, g$, $\Delta_{2}, \Delta_{3}, \cdots, \Delta_{7}>0$.

Proof. According to the game sequence of the two-stage CLSC with dominant retailer, the reverse recursion method is used to solve the problem. Under the assumption of scale parameter $k, g$, it is easy to through the Hessian matrix prove the profit function of the manufacturer $\pi_{m}^{M}(w, d, \tau)$ regard $w, d, \tau$ is a strictly concave function, according to the first-order condition, the best feedback functions of the manufacturer on the wholesale price of new products, the level of CSR invest and the recovery rate of waste products can be obtained as

$$
\begin{gathered}
w^{M}=\frac{g(a-\beta m)\left(2 k-\beta \Delta_{1}^{2}\right)+2 k g \beta c_{m}+k(\theta-\beta)\left(a-\beta m-\theta c_{m}\right)}{g \beta\left(4 k-\beta \Delta_{1}^{2}\right)-k(\theta-\beta)^{2}} \\
d^{M}=\frac{k(\theta-\beta)\left(a-\beta m-\beta c_{m}\right)}{g \beta\left(4 k-\beta \Delta_{1}^{2}\right)-k(\theta-\beta)^{2}} \\
\tau^{M}=\frac{g \beta\left(a-\beta m-\beta c_{m}\right) \Delta_{1}}{g \beta\left(4 k-\beta \Delta_{1}^{2}\right)-k(\theta-\beta)^{2}}
\end{gathered}
$$


Substituting formula (4)-(6) into formula (3), we know that $\pi_{r}^{M}(m) \operatorname{regard} m$ is a strictly concave function, and according to the first-order condition, the retailer's optimal unit profit $m^{M^{*}}$ can be obtained. Furthermore, substituting $m^{M *}$ into equations (4)-(6) respectively, the manufacturer's optimal wholesale price, optimal CSR invest level, and optimal recovery rate can be obtained in turn. According to $p^{M *}=m^{M *}+w^{M *}$, the optimal retail price $p^{M *}$ can be obtained, and then according to formula (1), the optimal market demand $q^{M *}$ can be obtained. Finally, substituting the above equilibrium variables into the profit functions of the manufacturer and the retailer respectively, the total profits of the manufacturer, the retailer and the CLSC can be obtained.

\subsection{The decision-making model under retailer 's CSR investment mode (Model R)}

Under the Model R, the retailer makes CSR investment, and the profit functions of the manufacturer and the retailer are respectively

$$
\begin{gathered}
\pi_{m}^{R}(w, \tau)=\left(w-c_{m}\right)(a-\beta p+\theta d)+\left(c_{m}-c_{r}-A\right) \tau(a-\beta p+\theta d)-k \tau^{2} \\
\pi_{r}^{R}(m, d)=(m-d)(a-\beta p+\theta d)-g d^{2}
\end{gathered}
$$

Theorem 2 Under the Model M, the optimal wholesale and retail prices for new products are respectively $w^{R *}=\frac{a g \Delta_{4}+\Delta_{8}}{\Delta_{9}}, p^{R *}=\frac{2 a g \Delta_{6}+\Delta_{10}}{\Delta_{9}}$; the optimal recovery rate and CSR investment level are respectively $\tau^{R *}=\frac{g \beta\left(a-\beta c_{m}\right) \Delta_{1}}{2 \Delta_{9}}, d^{R *}=\frac{k(\theta-\beta)\left(a-\beta c_{m}\right)}{\Delta_{9}}$; the optimal market demand is $q^{R *}=\frac{2 \mathrm{~kg} \beta\left(a-\beta c_{m}\right)}{\Delta_{9}}$. The total profits of manufacturer, retailer and system are respectively $\pi_{m}^{R *}=\frac{k g^{2} \beta\left(a-\beta c_{m}\right)^{2} \Delta_{2}}{\Delta_{9}^{2}}, \quad \pi_{r}^{R^{*}}=\frac{k g\left(a-\beta c_{m}\right)^{2}}{\Delta_{9}}$, $\pi_{s}^{R *}=\frac{k g\left(a-\beta c_{m}\right)^{2} \Delta_{11}}{\Delta_{9}^{2}}$

where, $\quad g \beta c_{m}\left(6 k-\beta \Delta_{1}^{2}\right)-k c_{m}(\theta-\beta)^{2}=\Delta_{8} \quad, \quad 2 g \beta \Delta_{2}-k(\theta-\beta)^{2}=\Delta_{9} \quad$, $k c_{m}\left(2 g \beta-(\theta-\beta)^{2}\right)+k(\theta-\beta)\left(a-\beta c_{m}\right)=\Delta_{10}, \quad 3 g \beta \Delta_{2}-k(\theta-\beta)^{2}=\Delta_{11}$. Under the assumption of scale parameter $k, g, \Delta_{8}, \Delta_{9}, \cdots, \Delta_{11}>0$.

Proof. Similar to the solution process of Theorem 1, due to space limitations, it is omitted and the proof is complete.

Proposition 1 When $\theta>\beta, d^{L *}>0$. Where, $L=\{M, R\}$.

Proposition 1 shows that only when the consumers are more sensitive to the CSR investment level than the price of new product, the companies will fulfill CSR through profit donations. And as stronger the consumer's social responsibility awareness, the higher the CSR investment level of corporate. This is also consistent with the relevant research conclusions of Modak et al. [5] when the domiant manufacturer to perform CSR through donations. At the same time, this paper further shows that no matter what kind of power-led 
CLSC, the premise for companies to perform CSR through profit donations is that consumers are more sensitive to the CSR investment level of corporate compared to the product prices. This also reveals that the government and all sectors of society can foster and enhance consumers' awareness of social responsibility to encourage companies to perform CSR more actively.

\section{Comparison of equilibrium results under different CSR investment modes}

Proposition 2 Under different CSR invest modes, $w^{M *}>w^{R *}, \tau^{M *}>\tau^{R *}$.

Proof. According to the relevant equilibrium results in theorem 1 and Theorem 2

$$
\begin{gathered}
w^{M *}-w^{R *}=\frac{k(\theta-\beta)\left(a-\beta c_{m}\right) \Delta_{12}}{2 \Delta_{3} \Delta_{9}}>0, \\
\tau^{M *}-\tau^{R *}=\frac{k g \beta\left(a-\beta c_{m}\right)(\theta-\beta)^{2} \Delta_{1}}{2 \Delta_{3} \Delta_{9}}>0,
\end{gathered}
$$

where, $g \beta\left(6 k-\beta \Delta_{1}^{2}\right)-k(\theta-\beta)^{2}+g \theta \Delta_{4}=\Delta_{12}$, Under the assumption of scale parameter $k, g, \Delta_{12}>0$.

Proposition 2 shows that compared with the retailer's CSR investment, the wholesale price of new products and the recycling rate of waste products are higher when the manufacturer makes CSR investment. In fact, as a follower, the manufacturer has limited channel profits, which are mainly derived from the wholesales of new products and the recycling and remanufacturing of waste products. Therefore, when the manufacturer makes CSR investment, in order to make up for her own cost expenditures in CSR investment, she will increase the remanufacturing revenue by increasing the recycling and remanufacturing of waste products; on the other hand, because the increasing effect of CSR investment on demand will be stronger than the decreasing effect of wholesale price increase, the manufacturer will set higher wholesale price to increase the sales income of new products.

Proposition 3 Under different CSR investment modes, $d^{M *}>d^{R *}, p^{R *}>p^{M *}$, $q^{M *}>q^{R *}$.

Proof. Since the proof process of Proposition 3 is similar to that of proposition 2, it is omitted here.

Proposition 3 shows that, compared with the retailer's CSR investment, when the manufacturer makes CSR investment, the retail price of new products is lower, while the CSR investment level of enterprises and the market demand for new products are higher.

Comparing Proposition 1 and Proposition 2, the trends of wholesale and retail prices of new products are not completely consistent. Wholesale prices are lower when the retailer makes CSR investment, and retail prices are lower when the manufacturer makes CSR investment. On the one hand, this shows that enterprises' CSR investment will bring certain cost increase. Therefore, the manufacturer will raise wholesale price correspondingly when she invests in CSR, while the retailer will raise retail price accordingly when she invests in CSR. On the other hand, it also shows that in the CLSC, enterprises' CSR input behaviour indirectly affects their pricing decisions, and different main enterprises' CSR input has different influences on them.

$\begin{array}{ccccr}\text { Proposition } 4 & 4 & \text { Under different } & \text { CSR } & \text { investment modes, } \\ \pi_{m}^{M *}>\pi_{m}^{R^{*}}, \pi_{r}^{M^{*}}>\pi_{r}^{R^{*}}, \pi_{r}^{M^{*}}>\pi_{m}^{M^{*}}, \pi_{r}^{R^{*}}>\pi_{m}^{R^{*}}, \pi_{s}^{M *}>\pi_{s}^{R^{*}} & \end{array}$

Proof. Since the proof process of Proposition 4 is similar to that of proposition 2, it is 
omitted here.

Proposition 4 shows that, compared with the retailer's CSR investment, the manufacturer, retailer and CLSC system obtain greater profits when the manufacturer's CSR investment. And regardless of whether the retailer makes CSR investment, the retailer, as the dominant player, always gets more profits than the manufacturer.

In general, from the perspective of consumers, society and environment, as well as from the perspective of improving the profits and CSR investment level of members of CLSC, compared with the CSR investment of the dominant retailer, the manufacturer makes CSR investment can achieve better results. This conclusion has the certain practical significance, in reality, in the retailer-led CLSC, the retailer as the dominant player, can motivate the manufacturer to actively undertake CSR and strive to improve CSR investment level by formulating reasonable pricing strategies, which is extremely beneficial to the CLSC members and whole system, consumers and the environment.

\section{Conclusion}

Based on a closed-loop supply chain composed of a manufacturer and a dominant retailer, this paper discusses the preconditions for the manufacturer and retailer to fulfil CSR through profit donation and the influence of different CSR investment modes on the pricing decision of CLSC. The main conclusions are as follows: 1) No matter what kind of CSR investment mode, only when consumers are more sensitive to the CSR investment level than to the price, the manufacturer and retailer will fulfil CSR through profit donation. 2) Whether from reducing the retail price of products, increasing the recovery rate of waste products, or increasing the CSR investment level and increasing the overall profit of CLSC system, the manufacturer makes CSR investment is always better than the retailer. 3) Consumers are the key factor to determine the CSR investment level. Therefore, as a market regulator, the government can not only increase consumer awareness of social responsibility through publicity and education, to encourage companies to actively perform CSR, but also through joint the dominant retailer to jointly formulate reasonable pricing strategies to encourage manufacturers to perform and increase CSR investment level.

Since this article focuses on the analysis of the situation when the market demand is determined, and still assumes that the CLSC system belongs to the simple structure of "one-to-one", this is also the research deficiency of this article. Future research can consider issues such as pricing decision and coordination in a CLSC with multiple CSR actors under random demand.

Funding: This research is supported by the National Nature Science Foundation of China (Grant No. 71701056), and Nature Science Foundation of Heilongjiang Province (Grant No. G2018007), and Fundamental Research Foundation for Universities of Heilongjiang Province (Grant No. LGYC2018JC056).

\section{References}

1. Zhao J J, Wang C X, Xu L. Decision for pricing, service, and recycling of closed-loop supply chains considering different remanufacturing roles and technology authorizations[J]. Computers \& Industrial Engineering, 2019, 132(6): 59-73.

2. Savaskan R C, Bhattacharya S, Wassenhove L N V. Closed-loop supply chain models with product remanufacturing[J]. Management Science, 2004, 50(2): 239-252.

3. Reverte C, Gómez-Melero E, Cegarra-Navarro J G. The influence of corporate social responsibility practices on organizational performance: evidence from eco-responsible 
Spanish firms[J]. Journal of Cleaner Production, 2016, 112(1): 2870-2884.

4. Panda S, Modak N M, Cárdenas-Barrónc L E. Coordinating a socially responsible closed-loop supply chain with product recycling[J]. International Journal of Production Economics, 2017, 188(1): 11-21.

5. Modak N M, Kelle P. Using social work donation as a tool of corporate social responsibility in a closed-loop supply chain considering carbon emissions tax and demand uncertainty[J/OR]. Journal of the Operational Research Society, 2019, DOI: 10.1080/01605682.2019.1654413.

6. Dai L L, Shu T, Chen S, et al. CSR remanufacturing supply chains under WTP differentiation[J]. Sustainability, 2020, 12(5): 2197-2216.

7. Liu Y Z, Xiao T J. Pricing and collection rate decisions and reverse channel choice in a socially responsible supply chain with green consumers[J]. IEEE Transactions on Engineering Management, 2020, 67(2): 483-495.

8. Wang Y, Wang Z, Li B Y, et al. Closed-loop supply chain models with product recovery and donation[J]. Journal of Cleaner Production, 2019, 227(1): 861-876.

9. Modak N M, Kazemi N, Cárdenas-Barrónc L E. Investigating structure of a two-echelon closed-loop supply chain using social work donation as a Corporate Social Responsibility practice[J]. International Journal of Production Economics, 2019, 207(1): 19-33. 